\title{
C - reactive protein of cerebrospinal fluid, as a sensitive approach for diagnosis of neonatal meningitis
}

\author{
Shima Javadinia ${ }^{1}$, Mohsen Tabasi ${ }^{2}$, Mehri Naghdalipour ${ }^{3}$, Najmosadat-Atefi ${ }^{3}$, Ramin Asgarian ${ }^{3}$, \\ Jamil Kheirvari Khezerloo ${ }^{4}$, Azardokht Tabatabaei ${ }^{3}$
}

1. Department of Medicine, School of Medicine, Zabol University of Medical Sciences, Zabol, Iran.

2. Legal Medicine Research Center, Legal Medicine Organization, Tehran, Iran.

3. Research Center of Pediatric infectious diseases, Rasoul Akram Hospital, Iran University of Medical Sciences, Tehran, Iran.

4. Young Researchers and Elite Club, Tehran Medical Sciences Branch, Islamic Azad University, Tehran, Iran.

\begin{abstract}
Background: Meningitis, is a potentially life-threatening condition that can rapidly progress to permanent brain damage, neurologic problems, and even death. Bacteria and viruses cause the great majority of meningitis disease in infants and children. CRP is used mainly as a marker of inflammation.

Objective: This study was conducted to assess the diagnostic value of CSF-CRP levels for differentiating between septic (bacterial) and aseptic infantile meningitis.

Methods: 49 hospitalized infants aged less than two months with suspected meningitis were enrolled in a cross-sectional analytic study. All of patients underwent lumbar puncture to obtain CSF. smears, cultures, cytological and biochemical analysis and latex agglutination testing were carried out on all CSF samples. Latex agglutination test was carried out on all CSF samples using a commercially available kit. CSF-CRP level of all infants was measured using the immunoturbidometric technique.

Results: Of 49 infants in this study, 20 and 29 cases were diagnosed as septic and aseptic meningitis, respectively. The CRP levels were obtained as $0.95 \pm 0.68 \mathrm{mg} / \mathrm{L}$ in septic and $0.16 \pm 0.36 \mathrm{mg} / \mathrm{L}$ in aseptic meningitis groups and this difference was statistically significant $(\mathrm{p}<0.001)$ between the two groups $(0.79 \pm 0.32 \mathrm{mg} / \mathrm{L})$. Based on the ROC curve, cut off levels for CRP was obtained $0.17 \mathrm{mg} / \mathrm{L}$. At this level, there was $95 \%$ sensitivity and $86 \%$ specificity to differentiate septic and aseptic meningitis.

Conclusion: CSF-CRP has suitable diagnostic value in distinguishing between infantile bacterial from aseptic meningitis especially in cases of negative bacterial culture of the blood and spinal fluid.
\end{abstract}

Keywords: C-reactive protein, cerebrospinal fluid, septic/aseptic meningitis, infant, diagnostic value.

DOI: https://dx.doi.org/10.4314/ahs.v19i3.10

Cite as: Javadinia S, Tabasi M, Naghdalipour M, Atefi N, Asgarian R, Khezerloo JK, Tabatabaei A. C - reactive protein of cerebrospinal fluid, as a sensitive approach for diagnosis of neonatal meningitis. Afri Health Sci. 2019;19(3): 2372-2377. https:// dx.doi. org/10.4314/abs.v19i3.10

\section{Introduction}

Meningitis is one of the dangerous infections associated with significant morbidity and mortality (1-8\%) through-
Corresponding author:
Azardokht Tabatabaei,
Research Center of Pediatric
infectious diseases,
Rasoul Akram Hospital,
Iran University of Medical
Sciences, Tehran, Iran.
Tel: +982166516049,
Fax: +982166516049
Email: azardokht_tabatabaei@yahoo.com

out the world ${ }^{1,2}$. The exact incidence of meningitis in children and infants is unknown, however diagnosis of meningitis should be considered as a major differential criteria in newborn with high fever and altered level of consciousness ${ }^{3}$. Although viral infection has been reported more than other microbial meningitis ${ }^{4,5}$, the infection caused by bacteria is a more significant problem in most of country in the world, especially in developing countries $^{6,7}$.

Antimicrobial therapy has great impacts on neurological complications and survival rate; so early diagnosis of bacterial meningitis from viral meningitis or meningoencephalitis is important for appropriate treatment, Prevention of anti-microbial drug resistance and achieving good outcomes $^{1,8}$.

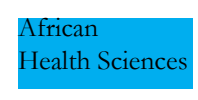

2372
(C) 2019 Javadinia et al. Licensee African Health Sciences. This is an Open Access article distributed under the terms of the Creative commons Attribution License (https://creativecommons.org/licenses/BY/4.0), which permits unrestricted use, distribution, and reproduction in any medium, provided the original work is properly cited. 
There are some problems in diagnosis of bacterial and viral meningitis using common laboratory tests, especially in children such as low sensitivity, time consuming laboratory procedures and changes in glucose and protein levels and also cell count of cerebrospinal fluid due to inappropriate and inadequate antibiotic therapy ${ }^{8,9}$. Latex agglutination is a rapid and sensitive approach for diagnosis of meningitis, but not available for routine use in developing countries ${ }^{10}$. Inflammatory marker measurement, blood cell count and blood culture were considered the gold standard methods for diagnosis of bacterial meningitis $^{11,12}$. There are several biochemical indicators in CSF that useful to diagnosis of bacterial infection as lactate, lactate dehydrogenases, c-reactive protein, ferritin, and cytokines $^{9,13}$. Also CSF lactate is a potential marker for diagnosis of bacterial meningitis but less useful if it has a low concentration ${ }^{14}$. In general we need an easy and comprehensive test for the early diagnosis of bacterial meningitis ${ }^{15}$.

For several years, serum CRP has been used for differentiation between bacterial and viral infections in developed countries $^{16}$. recently, it has been suggested that measurement of CRP in CSF is reliable, sensitive and easy test for rapid diagnosis of meningitis ${ }^{15,17,18}$, but it is not an alternative of examination of CSF biochemistry, cytology and culture ${ }^{15}$.

In a study by Bansal ${ }^{15}$ to estimate the level of CSF-CRP quantitatively in 121 children with meningitis via immuno-turbidimetry method, was concluded that CSF-CRP is a useful test to differentiate pyogenic meningitis from tubercular meningitis, viral meningoencephalitis and other non-meningitis CNS disorders. Also detection of CSFCRP helps in the choice of appropriate antibiotic and the duration of therapy ${ }^{15}$.

A study by Kalpana ${ }^{19}$, showed that CSF CRP screening yielded results with a higher specificity than blood CRP; hence, it can be a supportive test along with CSF cytology, biochemistry, and microbiology for diagnosing meningitis ${ }^{19}$.

In study by Bengershom ${ }^{20}$ on children with suspected meningitis, CSF-CRP level cut off was obtained as 0.4 $\mathrm{mg} / \mathrm{L}$ and the sensitivity and specificity values were $94 \%$ and $100 \%$, respectively ${ }^{20}$.

Corrall $^{1}$ shown that CSF- CRP was positive in all children with bacterial meningitis, $100 \%$ sensitivity and $94 \%$ spec- ificity was observed in comparison to control group ${ }^{1}$.

Several CRP detection methods are now available for measuring CRP values. The routine method for serum and CSF-CRP is qualitative or semi quantitative agglutination ${ }^{2}$, and this method was used in current research. The aim of this study was assessment of CSF-CRP in the infants with meningitis and evaluation of diagnostic value of this marker for distinguishing septic (bacterial) and aseptic infantile meningitis.

\section{Materials and methods}

This cross-sectional study was conducted in pediatric infectious diseases center of two teaching hospitals in Tehran from February through July 2015. The sample size obtained based on previous similar research ${ }^{21}$. A non-probability sampling of hospitalized infants was done and sampling continued until the completion of the required number. Thus 49 infants under two-months of age, with suspected meningitis, were enrolled in the research. These did not have any history of neuroses disorder or any contraindications for aspiration of CSF, and absence any antibiotic therapy in the last week through a questionnaire provided by their parents. The suspected diognosis of meningitis was introduced on clinical and laboratory findings. In other words, a lumbar puncture has been done on the infants during the sampling and suspected cases of meningitis received a fully assessment of CSF cytology, glucose and protein levels analysis. In addition, CRP concentration and total and differential WBC were measured. Gram staining of CSF, culture and latex agglutination testing were performed for diagnosis of bacterial meningitis. Septic meningitis was defined by a CSF leukocyte count of $100-10000 / \mathrm{m}^{3}$ with polymorphonuclear neutrophils of $>50 \%$, a CSF glucose level $<2.3$ blood sugar level and a CSF protein level of 100$500 \mathrm{mg} / \mathrm{dl}$.

Latex agglutination test was carried out on all CSF samples using a commercially available kit to differentiate septic and aseptic meningitis. A drop of CSF and a drop of latex reagent were mixed on a clean tile and the mixture was microscopically observed for agglutination. Aggregating of latex particles within two minutes was considered as positive. The CSF-CRP level was measured using quantitative turbidometric method. Finally, all of data were entered into the data collection form and Statistical analysis was performed using SPSS version 19 software. 
The frequencies of age, sex. WBC count, glucose, protein and CRP level were calculated via descriptive statistics. The different of CRP level between Septic and aseptic meningitis were determined through the Wilcoxon test. The receiver-operating characteristic (ROC) curve was used for determination of the cut off level for CSF-CRP to differentiate septic and aseptic meningitis.

\section{Results}

Out of 49 infants examined in this study, 28 (57.2\%) cases were male and $21(42.8 \%)$ were female. The mean and SD of age was $22.6 \pm 11.8$ days and the range was from 2 to 48 days. 20 cases were diagnosed as septic and 29 cases were diagnosed as aseptic meningitis. There was no significant difference between the two groups on sex and age $(\mathrm{P}$-Value $=0.1)($ Table1)

Table 1. Frequency of sex, age and CRP levels in neonates.

\begin{tabular}{|c|c|c|c|c|c|c|}
\hline \multirow[t]{2}{*}{ Infant } & \multicolumn{2}{|c|}{ sex } & \multicolumn{2}{|c|}{ age } & \multicolumn{2}{|c|}{ CRPlevel (mg/L) } \\
\hline & Male & Female & Mean & SD & Mean & SD \\
\hline Septic meningitis & $57.9 \%$ & $42.1 \%$ & 25.68 & 11.03 & 0.95 & 0.68 \\
\hline Aseptic meningitis & $55.2 \%$ & $44.8 \%$ & 20.58 & 12.17 & 0.16 & 0.36 \\
\hline P- value & \multicolumn{2}{|c|}{1.000} & \multicolumn{2}{|c|}{0.1} & \multicolumn{2}{|c|}{0.000} \\
\hline
\end{tabular}

CSF-CRP level significantly increased in septic infection

in comparison to aseptic meningitis $(\mathrm{P}-$ Value $=0.0)$ in the Wilcoxon test (Tables 1 and 2).

Table 2. The relationship between CSF-CRP level and statistical indicators.

\begin{tabular}{ll}
\hline Variables & CRP (mg/L) \\
\hline Cut off level & 0.17 \\
Sensitivity (\%) & $95 \%$ \\
Specificity (\%) & $86 \%$ \\
Positive likelihood Ratio & 6.7 \\
Negative likelihood Ratio & 17.2 \\
Area under the ROC Curve & 0.912 \\
\hline
\end{tabular}

Area under the ROC curve was calculated 0.912. Cut off levels for CRP was obtained $0.17 \mathrm{mg} / \mathrm{L}$ in the ROC curve. ROC curve for differentiation between septic and aseptic meningitis is presented in Figure 1. 


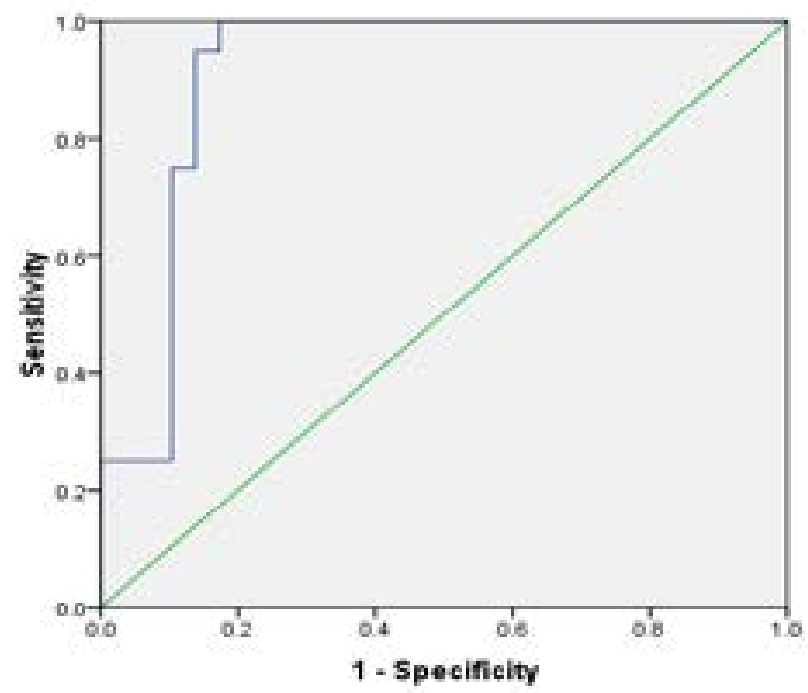

Figure 1. ROC curve for differentiation between septic and aseptic meningitis

\section{Discussion}

Polymorphonuclear leukocytosis, low glucose concentration, and increased protein concentration in CSF are characteristics for bacterial meningitis ${ }^{16}$. Sometimes, bacterial meningitis presents with atypical CSF manifestations $^{22}$ and the white blood cell count, total protein and glucose levels were often unreliable markers for differential diagnosis, greatly due to low sensitivity ${ }^{23}$. Glucose concentrations in the CSF of patients with viral meningitis often overlap those characteristic of bacterial meningitis; but, CRP, a non-specific indicator, was very reliable in estimating the type of infection ${ }^{24}$. CSF-CRP is not an alternative of examination of CSF biochemistry, cytology and culture ${ }^{15}$ and used to confirm the diagnosis, especially in restrictions on diagnostic tests.

Also CSF lactate is a potential marker for diagnosis of bacterial meningitis but less useful if it has a low concentration. Several investigators have found that CSF lactate determination does not contribute much to the diagnosis of bacterial meningitis. Therefore, quantitative determinations of CRP in CSF are most useful in monitoring the illness. Moreover, several intracranial disorders are known to cause CSF lactate increase ${ }^{14}$. The studies using CSF specimens collected from a variety of patients, regardless of the actual disease prevalence, may lead to false conclusions about the clinical usefulness of the CSF lactate tes $^{23}$. The CSF lactate test was more sensitive than the CSF-CRP test for diagnosis of bacterial meningitis, while the CRP test was more specific ${ }^{14}$. The result of current study shown CSF-CRP level in neonates with septic meningitis was higher than infants with aseptic meningitis. Findings from this study confirmed previous studies by Donald et al, Hanson et al, Trienekens et al. and Bansal et al. ${ }^{15,24-26}$ Corrall et al. has shown that CSF- CRP (latex agglutination test) was positive in all patients with bacterial meningitis, which 100\% sensitivity and 94\% specificity was observed in comparison to control group ${ }^{1}$. In study by Bengershom et al. on children with suspected meningitis, CSF-CRP level Cut off was obtained as $0.4 \mathrm{mg} / \mathrm{L}$ and the sensitivity and specificity values were $94 \%$ and $100 \%$, respectively ${ }^{20}$. Komorowski et al. reports that CSFCRP was effective indicator for rapid diagnosis of meningitis in $60 \%$ of adults ${ }^{27}$. In a study by Gray et al. CRP levels were greater than $100 \mathrm{ng} / \mathrm{ml}$, identified in $95 \%$ of bacterial meningitis ${ }^{28}$. Singh et al. reports that CRP level was positive in $84 \%$ of bacterial meningitis, and it was negative in all cases of aseptic meningitis. Also no correlation was observed between CSF-CRP level as well as total and differential cell count in the cerebrospinal fluid of septic cases ${ }^{29}$. Moreover, there was significant correlation between results of CSF-CRP level and positive septic meningitis. Therefore, determination of CSF-CRP has 
significant sensitivity for early differentiation of types of meningitis. There was some limitation in this study such as difficulty of access to samples and expensive diagnostic tests, and due this limitations, we used a few samples for analysis.

\section{Conclusion}

It can be concluded that, in addition to current conventional diagnostic methods (biochemistry, cultures and smears), CSF-CRP is a simple, rapid and accurate approach for the laboratory diagnosis of meningitis, especially in cases of negative result of bacteria in the blood and spinal fluid. Also, the CSF-CRP can be a diagnostic marker for differentiation of purulent and non-purulent meningitis. On balance, the above mentioned results showed that CSF-CRP level can be a diagnostic marker to differentiate septic and aseptic meningitis.

\section{Conflict of interest}

There is no conflict of interest.

\section{Acknowledgments}

The authors would like to express their gratitude to nursing of Bahrami Hospital and research center of pediatric infectious diseases for their financial support grants 131/13609. Also, we are thankful to Dr. Ali Badamchi for his technically assistance in this project.

\section{References}

1. Corrall CJ, Pepple JM, Moxon ER, Hughes W'T. C-reactive protein in spinal fluid of children with meningitis. The Journal of pediatrics. 1981;99(3):365-9.

2. Swartz M. Acute bacterial meningitis. Infectious diseases. 1998;1:1160.

3. Krogstad P. Osteomyelitis and septic arthritis. Textbook of pediatric infectious diseases. 2004.

4. Attia J, Hatala R, Cook DJ, Wong JG. Does this adult patient have acute meningitis? JAMA. 1999;282(2):17581.

5. Logan SA, MacMahon E. Viral meningitis. BMJ: British Medical Journal. 2008;336(7634):36.

6. Carbonnelle E. Laboratory diagnosis of bacterial meningitis: usefulness of various tests for the determination of the etiological agent. Medecine et maladies infectieuses. 2009;39(7-8):581-605.

7. Brouwer MC, Tunkel AR, van de Beek D. Epidemiology, diagnosis, and antimicrobial treatment of acute bacterial meningitis. Clinical Microbiology Reviews. 2010;23(3):467-92. 8. Cho SH, Lee HB, Lee KS. Clinical Study of Cerebrospinal Fluid Lactate Levels in Children with Menigitis. Journal of the Korean Pediatric Society. 1984;27(5):475-82.

9. Straus SE, Thorpe KE, Holroyd-Leduc J. How do I perform a lumbar puncture and analyze the results to diagnose bacterial meningitis? JAMA. 2006;296(16):201222.

10. Sanya E, Taiwo S, Azeez O, Oluyombo R. Bacteria meningitis: problems of empirical treatment in a teaching hospital in the tropics. The Internet Journal of Infectious Diseases. 2006;6(1).

11. Tunkel AR, Hartman BJ, Kaplan SL, Kaufman BA, Roos KL, Scheld WM, et al. Practice guidelines for the management of bacterial meningitis. Clinical Infectious Diseases. 2004;39(9):1267-84.

12. Chaudhuri A, Martin P, Kennedy P, Andrew Seaton $\mathrm{R}$, Portegies P, Bojar M, et al. EFNS guideline on the management of community-acquired bacterial meningitis: report of an EFNS Task Force on acute bacterial meningitis in older children and adults. European Journal of Neurology. 2008;15(7):649-59.

13. BullenJ, Rogers HJ, Griffiths E. Role of iron in bacterial infection. Current Topics in Microbiology and Immunology: Springer, 1978. p. 1-35.

14. Lindquist L, Linne T, Hansson L-O, Kalin M, Axlesson G. Value of cerebrospinal fluid analysis in the differential diagnosis of meningitis: a study in 710 patients with suspected central nervous system infection. European Journal of Clinical Microbiology and Infectious Diseases. 1988;7(3):374-80.

15. Bansal S, Gupta R, Gupta P, Kakkar M, Malhotra A, Bansal S. Quantitative levels of C-reactive protein in cerebrospinal fluid in children with bacterial and other meningitis. Journal of Evolution of Medical and Dental Sciences Vol2. 2013(25):4594-8.

16. Peltola H. C-reactive protein for rapid monitoring of infections of the central nervous system. The Lancet. 1982;319(8279):980-3.

17. Nagarathna S, Veenakumari H, Chandramuki A. Laboratory diagnosis of meningitis. Meningitis: In Tech; 2012.

18. Kawamura M, Nishida H. The usefulness of serial C-reactive protein measurement in managing neonatal infection. Acta Paediatrica. 1995;84(1):10-3. 
19. Malla KK, Malla T, Rao KS, Basnet S, Shah R. Is cerebrospinal fluid C-reactive protein a better tool than blood C-reactive protein in laboratory diagnosis of meningitis in children? Sultan Qaboos University Medical Journal. 2013;13(1):93.

20. Gershom EB, Briggeman-Mol G, de Zegher F. Cerebrospinal fluid $\mathrm{C}$-reactive protein in meningitis: diagnostic value and pathophysiology. European Journal of Pediatrics. 1986;145(4):246-9.

21. Konstantinidis T, Cassimos D, Gioka T, Tsigalou C, Parasidis T, Alexandropoulou I, et al. Can procalcitonin in cerebrospinal fluid be a diagnostic tool for meningitis? Journal of Clinical Laboratory Analysis. 2015;29(3):169-74.

22. Sakushima K, Hayashino Y, Kawaguchi T, Jackson JL, Fukuhara S. Diagnostic accuracy of cerebrospinal fluid lactate for differentiating bacterial meningitis from aseptic meningitis: a meta-analysis. Journal of Infection. 2011;62(4):255-62.

23. Rutledge J, Benjamin D, Hood L, Smith A. Is the CSF lactate measurement useful in the management of children with suspected bacterial meningitis? The Journal of Pediatrics. 1981;98(1):20-4.
24. Hansson L-O, Lindquist L, Linne T, Sego E. Quantitation of C-reactive protein in cerebrospinal fluid and serum by zone immunoelectrophoresis assay (ZIA). Journal of Immunological Methods. 1987;100(1-2):191-5.

25. Donald PR, Strachan AF, Schoeman JF, De Beer FC. Cerebrospinal fluid C-reactive protein in infective meningitis in childhood. The Journal of Laboratory and Clinical Medicine. 1985;106(4):416-23.

26. Trienekens P, Willems F, Zanen H. Significance of C-reactive protein in spinal fluid. Clinical Chemistry. 1985;31(2):345-.

27. Komorowski RA, Farmer SG, Knox KK. Comparison of cerebrospinal fluid C-reactive protein and lactate for diagnosis of meningitis. Journal of Clinical Microbiology. 1986;24(6):982-5.

28. Gray BM, Simmons DR, Mason H, Barnum S, Volanakis JE. Quantitative levels of C-reactive protein in cerebrospinal fluid in patients with bacterial meningitis and other conditions. The Journal of Pediatrics. 1986;108(5):66570.

29. Singh N, Arora S, Kahlon PS. Cerebrospinal fluid C-reactive protein in meningitis. Indian Pediatr. 1995;32(6):6878. 